\title{
Don Quijote y Sancho Panza, personajes en una máscara de mojiganga novohispana: El vejamen de don Félix Luna (siglo XVIII)
}

\author{
JUDITH FARRÉ*
}

Entre los muchos indicios que atestiguan el impacto que alcanzó la publicación de la primera parte del Quijote, figura su inmediata incorporación a la cultura festiva ${ }^{1}$. La presencia de motivos y personajes procedentes de la novela cervantina se registra en varias fiestas populares ya desde el mismo año de $1605^{2}$. Siempre con una intención lúdica, la impronta de la novela se hará notar como argumento festivo en mascaradas celebradas tanto en España como fuera de ella. Así, en América, la primera constancia de este tipo de intervenciones quijotescas surge en el campo minero de Pausa, en Perú, a raíz de los festejos por el nombramiento del marqués de Montesclaros como nuevo virrey $(1607)^{3}$. Otras noticias procedentes del Perú se sitúan en las ceremonias públicas por el nacimiento del príncipe Baltasar Carlos (Lima, 1630) ${ }^{4} \mathrm{y}$, en el ámbito universitario, en las de defensa del estatuto de la con-

* CSIC.

1. Entre otros, resultan fundamentales los trabajos de Francisco López Estrada, «Fiestas y literatura en los Siglos de Oro: la Edad Media como asunto festivo», Bulletin Hispanique, 84 (1982), pp. 291-327 y María Luisa Lobato, «El Quijote en las mascaradas populares del siglo XVII», en José Ángel Ascuence Arrieta, Cervantes. Estudios en la víspera de su centenario, Kassel, Reichenberger, 1994, vol. II, pp. 577-604.

2. Véase, por ejemplo, Aurelio Vargas Díaz-Toledo, «Fastiginia de Tomé Pinheiro da Veiga. Edición de los días 10 y 28 de junio de 1605: primer documento de la recepción del Quijote», Anales cervantinos, XXXIX (2007), pp. 309-343.

3. Francisco Rodríguez Marín, El Quijote y don Quijote en América, Madrid, Librería de los sucesores de Hernando, 1911, pp. 74-118. Otra edición más reciente del texto a cargo de José Manuel Lucía Megías y Aurelio Vargas Díaz-Toledo: «Don Quijote en América: Pausa, 1607 (Facsímil y edición)», Literatura: teoría, historia y crítica, 7, 2005, pp. 203-244.

4. Juan Antonio Suardo, Diario de Lima 1629-1639, ed. Rubén Vargas Ugarte, Lima, Universidad Católica del Perú-Instituto de Investigaciones Históricas, 1936, pp. 143-144; Miguel Lasso de la 
cepción sin mancha de la Virgen María (Lima, 1656) . Por lo que respecta a Nueva España, la primera noticia se recoge a raíz de la máscara que organizó el gremio de plateros de la ciudad de México para celebrar la beatificación de san Isidro $(1621)^{6}$.

Además de este tipo de celebraciones ocasionales ligadas a circunstancias concretas, la presencia festiva de los dos protagonistas cervantinos encaja bien en otro tipo de diversiones propias del calendario universitario: los paseos ridículos, vítores y vejámenes que seguían a la obtención del grado de doctor, a las graduaciones y a los exámenes de oposición a cátedra. En este contexto estudiantil, son frecuentes las alusiones burlescas al Quijote. Prueba de ello es otro vejamen novohispano de 1788 (Vejamen que dijo el licenciado don Pedro José Sánchez Meza la tarde del 27 de diciembre de 1788 en el Teatro de los dioses), en el que Sánchez Meza desecha la graciosa alegoría que hizo Muro, uno de los estudiantes del curso, por no estar representados todos los graduandos, aunque le reconoce su ingenio al asignar un personaje a cada uno de los dieciocho:

\begin{abstract}
A buen tiempo supe vuestra consulta sobre la cifra del célebre caballero don Quijote de la Mancha y su historia; acordando la graciosa alegoría y distribución que hizo Muro; la que os conviene y ya refiero en honor de vuestro ingenio: Muro, don Quijote; Valle, doña Dulcinea; Cos, Sancho Panza; Duval, el Asno de Sancho; Velázquez, don Fernando; Cano, el Arriero que con don Quijote tuvo contienda la noche de velación de armas; Pérez, el Ama; Galíndez, la Sobrina; Carrera, Cardenio; Moreno, Lucinda; García, el Cura; Rodríguez, el Barbero; Gaytán mayor, el Duque; Gaytán minor, la Duquesa; Báez, Dorotea; Márquez, el Ventero que armó caballero a don Quijote; Andueza, Teresa Panza; Herrera, el Rocinante de don Quijote; cuya lista en confianza me dio Andueza; lo digo a todos en secreto y encargo que con secreto lo comuniquéis a todos; no luego me culpe mi Teresa de tan poca fidelidad ${ }^{7}$.
\end{abstract}

El vejamen no responde a defectos reales del graduando o del opositor, sino que, como contrapunto, forma parte de toda la ceremonia de investidura en el nuevo rango académico. Por ello, en el horizonte de expectativas de su recepción, debe tenerse en cuenta que persigue ponderar de manera burlesca los defectos de una persona, lo que, en palabras de Abraham Madroñal, supone asumir la convención de que «no se dice toda la verdad y de que lo que se

Vega, «Apuntes sobre la Lima del siglo XVIII», Mercurio peruano, 24, 184 (1942), p. 362 y López Estrada, 1982, p. 294, nota 6.

5. Lobato, 1994, p. 578.

6. Luis González Obregón, México viejo, Madrid, Alianza, 1999, pp. 270-272 e Irving A. Leonard, La época barroca en el México colonial, México, Fondo de Cultura Económica, 1976, pp. 177. 179.

7. Elena Omacini, «Teatro de los dioses de Pedro José Sánchez Meza. Estudio preliminar, edición y notas» en José M. Mariluz Urquijo, Elena Omacini y Daisy Rípodas Ardanaz, Tres estudios novohispanos. Sociedad. Letras. Artes, Buenos Aires, Libros de Hispanoamérica, 1983, p. 67. 
expresa es una caricatura de la realidad $»^{8}$. Son, pues, piezas de circunstancias, que se dirigen a un público cerrado, ya que las burlas apuntan directamente a los ingenios congregados, quienes aparecen caricaturizados a partir de la deformación burlesca de algún rasgo característico, físico o moral.

El autor y el auditorio de este tipo de piezas son cultos, de ahí las referencias a obras literarias o la inserción de algunas citas en latín. En este sentido, cabe decir que una de las condiciones establecidas es que los vejámenes fueran escritos en castellano ${ }^{9}$, aunque ello no impedía que se incluyeran algunas citas de extensión variable en latín. En el vejamen que nos ocupa éstas son mínimas y suelen referirse a indicaciones sobre su puesta en escena ${ }^{10}$ : «un arco con este lema: Non labori sed otio» (17r.); «Musica in luctu, intempestiva narratio» (20v.), o ejercer la función de citas clásicas que, como argumentos de autoridad, sustentan las opiniones del autor, aunque luego se ofrezca su traducción. Por ejemplo:

Ahora pues que nombro al Horacio se me [ocurren] un par de versos que trae en su Arte Poética, y que entenderá sin duda, si por lo poeta no ha dejado el arte:

Hic dum sublimeis versus, ructatur et errat, si veluti merulis intentus dicidit auceps in puteum foueame

Me ha venido gana de vertirlos al castellano, ya porque no tenga boca para decir «quien da el consejo, da el tostón», y ya porque es obra de misericordia corregir al que yerra:

Si cuando aquí se trata lo sublime, el Poeta se ocupare en cazar moscas, a ser vendrá como el que caza mirlas que divertido cae en una fosa. $(8 \mathrm{v} .-9 \mathrm{r} \text {. })^{11}$

Aunque quizá el rasgo que mejor puede definir la forma de los vejámenes ${ }^{12}$ es la combinación de prosa y verso. De este modo, el procedimiento habitual

8. Abraham Madroñal, «De grado y gracias». Vejámenes universitarios de los Siglos de Oro, Anejos de Revista de Literatura n. ${ }^{\circ}$ 66, Madrid, Consejo Superior de Investigaciones Científicas, 2005, p. 27.

9. Omacini, 1983, p. 57

10. Como señala Madroñal, una de las primeras cuestiones a considerar al trazar las características del vejamen es su oralidad: «el vejamen es hablado, más diría, se pone en escena casi con el efectismo de una representación dramática o de un discurso o sermón, por eso se utilizarán todos los recursos de estos (gesticulación, visajes de rostro, actuación, guiños al oyente...)», Madroñal, 2005, p. 77.

11. De aquí en adelante, las citas que aparecen en este apartado de introducción señalando entre paréntesis su paginación proceden del «Vejamen de don Félix Luna» que se edita en el apartado final.

12. Para el estudio de los vejámenes, son fundamentales, además de los ya citados de Omacini (1983) y Madroñal (2005), los trabajos de Aurora Egido («Linajes de burlas en el Siglo de Oro» en Ignacio Arellano Ayuso et al. [coords.], Studia aurea: actas del III Congreso de la AISO [Toulouse, 1993], Toulouse-Pamplona, 1996, vol. 1, pp. 19-50; «Literatura efímera: oralidad y escritura en los 
consiste en la narración o la descripción en prosa que suele terminar con un colofón en verso, muchas veces acompañado de música. Así ocurre, por ejemplo, en el texto que editamos a continuación con las seguidillas que resumen el propósito del vejamen y el artificio que enmarca toda la burla:

Éste es mi modo de pensar — proseguí yo-. Óiganlo Vuestras Mercedes vaciado todo en estas seguidillas, pues a ocasiones suelen hacerme la voz las nueve hermanas que habitan el Pindo ${ }^{13}$ :

\author{
Si el pirrónico ${ }^{14}$ duda \\ de cuanto escribe \\ creyendo que se duerme \\ cuando se vive, \\ del tiempo de mi curso \\ no es mucho me imagine \\ que sólo ha sido un sueño \\ que mi delirio finge. \\ Soñantes y durmientes \\ han de venir a oírme, \\ pero yo bien distingo \\ los que han de distinguirse. \\ Verdades voy a hablaros \\ y no he de arrepentirme, \\ que ya se llegó la hora \\ de que yo me despique ${ }^{15}$. \\ Dejar rodar la bola ${ }^{16}$; \\ no hay que sentirse, \\ las moscas no se paran \\ con sacudirse ${ }^{17}$ : \\ he decidido esta tarde \\ sólo por reírme. (3r.)
}

Los vejámenes de academia y de grado comparten muchos de sus rasgos definitorios, lo cual se aprecia, en el caso que nos ocupa, en la sátira a Ezquirros y Cañas, alumnos del curso de Artes y, además, poetas:

certámenes y academias de los siglos de oro», Edad de oro, 7 [1988], pp. 69-88 y «Floresta de vejámenes universitarios granadinos [siglos XVII-XVIII]», Bulletin hispanique, 92, 1 [1990], pp. 309-332) y Francisco Layna Ranz ("Ceremonias burlescas estudiantiles [siglos XVI y XVII]: 1. "Gallos”», Criticón, 52 [1991], pp. 141-162 y «Dicterio, conceptismo y frase hecha: a vueltas con el vejamen», Nueva revista de filología hispánica, 44, 1 [1996], pp. 27-56).

13. nueve hermanas que habitan el Pindo: se refiere a las nueves musas, puesto que el Pindo, junto a Delfos, son espacios míticos de reunión para las musas.

14. pirrónico: «Lo mismo que escéptico» (Aut.).

15. despicar: «Desahogar, satisfacerse» (Aut.).

16. rodar la bola: «Frase vulgar que equivale a holguémonos y corran las cosas como quisieren. Úsanlo mucho los perdidos y que no reparan en los inconvenientes y resultas que suelen traer las acciones inconsideradas» (Aut.).

17. sacudirse las moscas: «Frase metafórica que vale lo mismo que mosquearse» (Aut.). 
[en] días pasados, que tuvimos los dos un certamen poético, nos pusimos como nuevos de [sátiras], pero había Vuestra Merced de ver los desfiguros ${ }^{18}$ de sus poesías, que eran tales que me estrecharon ${ }^{19}$ a decirle:

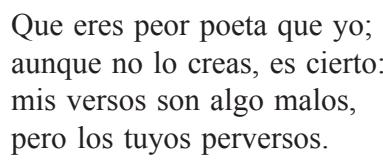

- Aun este verso no es de Vuestra Merced - le dije - y me atrevo a asegurar que se lo soplaron. Conozco bien a ambos y me consta son de lo peor que he oído. ¿Quién diablos — continué diciendo- les ha metido a poetas? Porque es necesario estar muy preocupados para que Vuestras Mercedes mismos no conozcan sus desatinos y abandonen esa pasión retobada ${ }^{20}$ que han concebido por sus abortos ${ }^{21}$, que así deben llamarse los mamarrachos poéticos que forman. $(24 \mathrm{v}$.)

El autor del Vejamen aprovecha la condición de poetas para la crítica a los dos estudiantes, lo cual sirve, además, para comprobar uno de los ataques más comunes en este tipo de certámenes poéticos: la sospecha sobre la verdadera autoría de los versos presentados ${ }^{22}$.

El texto que presentamos a continuación forma parte del vejamen por don Félix Luna que, a modo de sueño, sirve para clausurar el curso de Artes en la universidad de la ciudad de México, probablemente en la segunda mitad del siglo XVIII. Como expresa el autor en los endecasílabos iniciales: «Triste, solo, confuso y pensativo,/una idea o un modelo meditaba/para el vejamen que concluir debía/del curso de Artes la carrera larga» (1r.). No resulta posible precisar la fecha con exactitud, aunque ciertas alusiones apuntan hacia mediados del siglo XVIII, tales como la afirmación del autor en la que exclama que: «En mi vida había visto bailar los predicamentos; no en vano dicen que éste es el siglo ilustrado, en donde hasta los sones vulgares inspiran filosofía» $(26 \mathrm{v} \text {. })^{23}$.

18. desfiguro: «cosa ridícula» (DRAE).

19. En el manuscrito original: estracharon. Enmendamos el original dada la ausencia de testimonios de un supuesto verbo *estrachar, cuyo significado, por el contexto, lo acerca a la acepción de «constreñir a alguien mediante preguntas o argumentos a que haga o diga algo» (DRAE).

20. retobar: Lo mismo que rezongar («Gruñir, refunfuñar a lo que se manda, ejecutándolo de mala gana», DRAE).

21. aborto: «Metafóricamente usan de esta voz los poetas, cuando el mar, los montes u otras cosas no capaces de concebir arrojan de sí algo que contenían» (Aut).

22. Madroñal, 2005, p. 81.

23. También Vicente T. Mendoza apunta la hipótesis de esta fecha, pues comenta que se trata de «un manuscrito en un cuadernillo de papel de la época en cuyo frente dice: Siglo XVIII. En verdad debe pertenecer a la segunda mitad de este siglo, por los elementos literarios y musicales que encierra, casi todos derivados de la tonadilla escénica, la cual tuvo en nuestro Coliseo hacia esas fechas, un extraordinario auge» (Vida y costumbres de la Universidad de México, México, Instituto de Investigaciones Históricas, 1951, p. 40). 
Se trata de una obra que forma parte de una ceremonia pública, la clausura del curso de Artes, y que se dirige al colectivo de todos los estudiantes del curso que se graduaban; de ahí el artificio alegórico del sueño en el que irán desfilando todos los alumnos, lo que le permite al vejador repasar su desempeño en el curso ${ }^{24}$ y motejarlos como durmientes o soñantes:

Alto, pues yo no soy más que un soñante y mis discípulos no más que unos durmientes: yo he soñado que voy a leer Filosofía y ellos que se disponen a oírla. Pero ¡dioses! —exclamaba yo—, ¿qué género de durmientes será el que me ha tocado en suerte? En verdad que si hay mucha modorra serán continuadas las pesadillas, de suerte que si éste pasase a ser letargo -me replicó un amigo que soñaba conmigo-, al cabo del tiempo no serán filósofos ni aun por sueño, y en tratando sólo de dormir como unos patriarcas, yo fío que no seré mal profeta: a palos muera el pronóstico - le dije enfadado- . Ni soy tan ignorante que me persuada a que todos mis discípulos han de ser soñantes, ni me juzgo tan infeliz que todos hayan de ser durmientes. De todo habrá como en botica ${ }^{25}$ : unos soñarán conmigo y apurarán las sutilezas al discurso, y otros dormirán a pierna suelta, como suele decirse. $(2 \mathrm{v}$.)

La estructura, pues, es la característica del vejamen de academia, ya fijada por Carrasco Urgoiti: se inicia con la alusión a las dificultades por encontrar un pretexto alegórico en el que encuadrar el desfile de ingenios - normalmente el hallazgo recurre al sueño-, posteriormente siguen las semblanzas jocosas dedicadas a cada uno de los académicos satirizados, que terminan con una estrofa burlona, $y$, finalmente, el vejamen acaba con un fragmento de elogio a la Academia, que ha tenido que soportar todas las chanzas ${ }^{26}$.

El marco que se presenta al inicio del vejamen es el siguiente:

Quedome a obscuras y rendime al sueño

$y$, como sea verdad acreditada

que de aquellas especies más presentes

se excitan en durmiendo los fantasmas, soñé yo con mi curso; pero — icielos! -

qué figuras tan nuevas y tan raras

en el discurso de la media noche

en mi imaginación se presentaban,

cual suelen en el teatro los canceles

24. Es ésta una parte característica en estos vejámenes colectivos, tal y como señala Elena Omacini en su estudio de estas piezas en el siglo XVIII novohispano: «las tribulaciones del vejamista hasta hallar una alegoría en la que pudiera estar representado el curso, además, el anhelo de ser grato a la selecta concurrencia que prestigiaba el acto y la puntualización de que cuanto se dijera no encerraba malévola intención» («Vejamen al doctor en medicina Andrés Díaz, México, 1708», Investigaciones y ensayos. Academia Nacional de la Historia. Buenos Aires, 34, enero-junio [1983], p. 523).

25. de todo habrá como en botica: «Frases que explican la abundancia de cosas que hay en alguna parte» $(A u t)$.

26. María Soledad Carrasco Urgoiti, «Notas sobre el vejamen de academia en la segunda mitad del siglo XVII», Revista hispánica moderna, 31, 1/4 (1965), p. 102. 


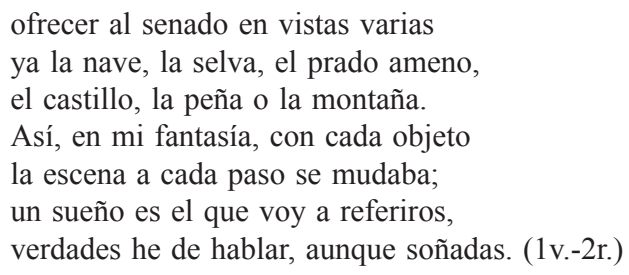

Así pues, el narrador anuncia la presencia de figuras nuevas y raras, lo que, sin duda, anticipa la estructura del desfile de figuras que, a semejanza del género entremesil, se constituye en el modelo compositivo del fragmento de la pieza que editamos. El propósito de hablar sobre verdades soñadas responde al objetivo que apuntábamos anteriormente como principal cometido del vejamen, puesto que la verdad que se presente será a medias con el fin de provocar la risa del auditorio; por ello, la ofensa hacia los personajes vejados no pretende en ningún caso ejercer las leyes de la crítica:
Al dar el vejamen a mi musa cito, y cuando tanto por mi gusto emprendo, ni preceptos del arte solicito, ni leyes de la crítica pretendo; no al [antojo] de aquéllas me limito, ni del nimio rigor de éstas me ofendo. Voy a hablar lo que el sueño me sugiere, que el poeta fingirá lo que quisiere. (2r.)

El carácter oral que impone la dimensión pública del vejamen, como parte de los actos tradicionales en este tipo de ceremonias universitarias, se expresa no sólo en las salutaciones iniciales del vejamen y en el transcurso del fragmento que editamos ( Y pues es tiempo que se sepa el contenido de aquellos versos que venían escritos en el pendón, silencio y al caso», 20r.), sino también en el apóstrofe con que se cierra el manuscrito:

Me resta, pues, pediros perdón de los yerros que he cometido en vuestro trato, y a vosotros otorgarlo. Yo sé muy bien que hablo delante de una Academia sabia, cuyo carácter es la prudencia, por lo que tendrá a bien disimular lo mal pulido y desaliñado de este papel, que no me hubiera atrevido a traer a este lugar respetable que ocupo, si una inveterada costumbre no canonizara semejantes piezas. (30v.)

Además de las alusiones al público presente, otro de los rasgos propios de la oralidad que caracteriza a la pieza son las referencias a la música con que se acompañaría su puesta en escena. Citaremos en esta ocasión algunos ejemplos extraídos de la pieza que nos ocupa: «pero antes de entrar a referirlo, dirá la música una tonadilla que les prepare a oír el sueño que a cada uno corresponde» (11v.) o «pero ya que es Vuestra Merced tan afecto a la música, será bien que le canten unas seguidillas» (24r.). Los rasgos de oralidad también se 
hacen patentes en los mexicanismos que encontramos dispersos a lo largo de todo el texto, sobre todo en los fragmentos en prosa (mecate, 15v.; huipil, 21v.; chichiltie, 22r...); aunque quizá uno de los ejemplos más significativos sea en verso, en el pasaje de las burlas hacia Clemente Espino y José María Oyer, donde las estrofas finales imitan la pronunciación de lenguas indígenas:

Con que ya que estos caballeros por su color, que es tan blanco como la leche del ocote ${ }^{27}$, parecen indios, la Música tocará el son que les toca:

Moncha pena te lo daba cuando el limosna pedías, y omitzquietoqui in tlacami hitlapopol hui tatita.

\section{2}

Cuando te ibas por el plaza a robar los pobres indios, omitzilhuiqui enojadas ma tlahuelilo mitzcuica.

\section{3}

Quietoa mo campagne oyer senechimaca mediesito, amonca lo respondías moztla yes tomin chobino.

\section{4}

Don Clemente mi señor, semica otiapiz miqui aya para beber moncho atol nosti otitlatlaniliaya. (28r.)

El pasaje concreto del fragmento que editamos se corresponde con la segunda parte característica de esta tipo de piezas: la presentación de cada uno de los alumnos del curso, con sus dotes particulares. En esta ocasión, los personajes vejados son, en primer término, Manuel Moreno, Francisco Gómez y José Pérez, quienes protagonizan tres jornadas de la comedia de La vida es sueño, que termina con una réplica del Poeta. Los vejámenes son textos escritos por autores cultos, y de ahí las numerosas alusiones a obras literarias que, en este caso, además de las del Quijote y La vida es sueño, evocan

27. ocote: «Aztequismo empleado como nombre vulgar de las plantas del género Pinus, coníferas de la familia especial de las pináceas [...] La madera es un combustible muy usado, haciéndola rajas, y sirve como tea para el alumbrado, entre la gente pobre y campesina [...]. "Parecía encanijada, de color abronzado, con el cutis tan pañoso que cualquiera diría que estaba sombreada con humo de ocote"» (Inclán, Astucia, t. I, p. 154); Francisco J. Santamaría, Diccionario de mejicanismos: razonado, comprobado con citas de autoridades, México, Porrúa, 1983, p. 768. Parece claro el juego que se elabora a partir del color blanco de la leche y el oscuro por su procedencia del ocote, para denotar la tez oscura de los dos estudiantes. 
obras teatrales como Un bobo hace ciento y Entre bobos anda el juego. A esta parodia inicial de la obra calderoniana, sin más transiciones que la caída del telón, le sigue una máscara de mojiganga en la que los protagonistas son José Antonio Rodríguez, José Manuel Mauriño, José María Bocarando y José Atanacio Aedo. En esta ocasión, los estudiantes representan, respectivamente, los papeles de personajes de la novela cervantina: don Quijote, Sancho, la dueña Dolorida y Dulcinea ${ }^{28}$. Se acompañan de un grupo de danza compuesto por otros cinco estudiantes (don Lorenzo Pérez, don Francisco Mendivil, don Miguel Arenal, don José Manuel Villarelo y don José María Aguilar) y dos músicos ${ }^{29}$, un órgano (don Martín Mauleón) y violín (don Mariano Gallegos).

La burla a los estudiantes vejados cubre varias facetas y se ajusta a las tendencias de estilización negativa de la sátira conceptista, «hasta el punto de que el individuo está casi siempre visto en función de dos peculiaridades ridículas, bien sean físicas o de carácter» ${ }^{30}$. En primer lugar, José Antonio Rodríguez, que ejerce de Quijote, es ridiculizado por su figura: «Venía don José Antonio Rodríguez a caballo, en la misma figura que pinta el mismo Miguel de Cervantes al ingenioso hidalgo don Quijote» (18r.). Lo burlesco de su descripción física se completa con la delgadez de su caballo que «tan al vivo representaba un esqueleto» (18r.). Don José Manuel Mauriño, el estudiante al que se asocia la figura de Sancho Panza, también imita «en todo a este leal escudero» (18r.), aunque su burla, además de precisar que «la máscara con que cubría la cara era muy semejante a la que se nos pinta en la historia» (18r.), se dirige hacia su retrato moral, ya que «aunque no es tonto en las producciones geniales que tiene, puede apostarlas al mismo Sancho Panza» (18r.). La demostración viene dada por dos enigmas que resuelve Mauriño (18r.-18v.), cuyas respuestas quizá evoquen una polisemia de sentido para definir al mismo Mauriño: el ratón (que, según Autoridades, en germanía significa «ladrón cobarde») y el mayate (que, según el $D R A E$, significa escarabajo y, en sentido coloquial, «hombre

28. Posteriormente, en la sátira a otro estudiante, don Miguel Arenal, aparecerá una nueva alusión a la novela cervantina, al compararle con Sansón Carrasco por su socarronería:

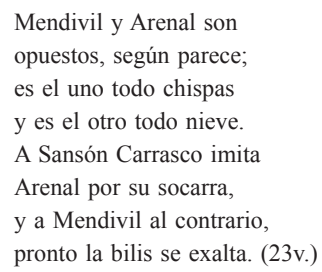

29. La mojiganga dramática «prototípica tiene una estructura musical y de baile en desfile o para-desfile: comienza muchas veces con una canción, se suceden luego intervenciones musicales que aúnan las escenas, y concluye con una coreografía grotesca que desborda el escenario y entronca con el desfile popular o festivo propiamente dicho», Catalina Buezo, La mojiganga dramática. De la fiesta al teatro, Kassel, Reichenberger, 1993, p. 320.

30. Carrasco Urgoiti, 1965, p. 100 . 
homosexual»). De hecho, éste es el estudiante que más descalificaciones morales recibe ya que se le acusa de simple y de no haber querido estudiar. Su simpleza se pone de manifiesto al intervenir en el diálogo ensartando una retahíla de refranes que enfadan a José Antonio Rodríguez:

porque he oído [decir] que donde las dan las toman, y que no hace la zorra [en] un año, cuanto paga en una hora; pero a mí tanto se [me] da de lo que va como de lo que viene, y eso de pagar los azotes al verdugo, no me acomoda, pues ojos que no ven corazón que no siente.

- Calla — le dijo enfadado don Rodríguez-, que ignoro a qué vienen tantos refranes como has ensartado en un momento. (19r.)

El vejamen también se refiere a alguna representación navideña en la que debía de haber participado, por la que se le reprocha su simpleza y se le satiri$z a$ por ser capaz de representar como pastor tartamudo en alguna pastorela:

—Entiendo bien la sátira — replicó Mauriño-, y conozco que me ha dicho Vuesa Merced, en términos disfrazados, que para hacer el papel de Bato en algún coloquio por tiempo de navidad tengo bastante suficiencia. Es cierto que soy sencillo por naturaleza, pero con algunos ribetes de malicioso. Pero ojo al tres, que si yo soy a propósito para pastor, otros son para nada. (19r.)

El mismo autor lo confirma en las quintillas que le dedica tras el retrato:

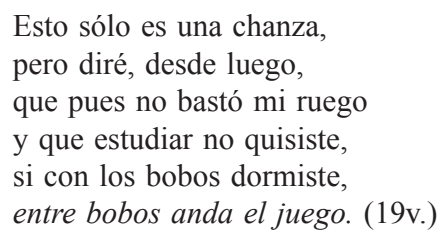

Atanasio Aedo y José María Bocarando representaban, respectivamente, a Dulcinea y a la dueña Dolorida. Sus descripciones, tal y como sugiere el disfraz travestido, evocan sobre todo la fealdad de sus rostros, que se acentúa con las alusiones a los encantamientos por parte de los «encantadores y malandrines» que a Dulcinea le han «trocado su color volviéndolo moreno y disfrazado su hermosura bajo el tosco velo de una soez aldeana» (18v.-19r.), mientras que a la dueña Dolorida llevan con tan «mal talante» (18v.).

\section{Criterios de edición}

La edición del texto que se presenta transcribe el manuscrito original depositado en el Archivo de la Biblioteca Nacional de Antropología e Historia de la ciudad de México (Colección Gómez de Orozco, n. ${ }^{\circ}$ 112) habiendo moder- 
nizado la ortografía de lo que no presenta distinto valor fonológico, tanto en lo que respecta a las grafías como a la acentuación y a la puntuación. Entre corchetes se marcan las palabras reconstruidas por conjetura debido a los rotos que afectan a algunos folios.

También se han incorporado los signos gráficos necesarios para marcar el estilo directo que en el texto aparecían como mera sucesión en prosa.

Una edición parcial del texto, ahora revisada, se presentó como apéndice en «La presencia festiva del Quijote en los virreinatos americanos» en Dramaturgia festiva y cultura nobiliaria, ed. Bernardo J. García y María Luisa Lobato, Madrid-Frankfurt, Iberamericana-Vervuert, 2007, pp. 385-416.

\section{Métrica}

$\begin{array}{ll}1-20 & \text { quintillas } \\ 21-32 & \text { silva } \\ 33-42 & \text { quintillas } \\ 43-54 & \text { silva } \\ 56-64 & \text { quintillas } \\ 1-4 & \text { cuarteto asonantado } \\ 1-10 & \text { quintillas } \\ 1-42 & \text { tercetos encadenados } \\ 1-40 & \text { quintillas } \\ 1-10 & \text { quintillas de cabo roto } \\ 1-30 & \text { quintillas con pie quebrado } \\ 1-42 & \text { seguidillas compuestas }\end{array}$




\section{EDICIÓN DEL VEJAMEN DE DON FÉLIX LUNA}

[Pasaron] estos caballeros tan pronto como lo digo, y se me [presentó] un teatro dispuesto para representar una comedia. [Tenía] en el frontispicio un arco con este lema: Non labori sed otio, y su traducción abajo que decía:

Si el trabajo aborrezco

el ocio y la [inacción] sólo apetezco.

Comedia famosa, su título:

La vida es sueño

Interlocutores
Don Manuel Moreno
Don José Pérez
Don Francisco Gómez
El Poeta

Jornada primera

Don Manuel Moreno

DON FRANCISCO GÓMEZ
Todo en esta vida humana como flor es que pasó, y la que hoy flor se soñó, es humo y polvo mañana. De saber no tengo gana, sólo dormir es mi empeño y en tan justo desempeño durmiendo a pierna tendida quiero pasar esta vida, puesto que la vida es sueño. Sueña el rico que atesora cuando sus talegas ${ }^{1}$ cuenta; sueña el que saber intenta cuando en argüir se acalora; el triste sueña que llora.

Todo es un sueño y así tengo la experiencia en mí, que durmiendo en todas partes al cabo del curso de Artes soñé que estudiante fui.

\section{Jornada segunda}

No hay vida más ligera que aquella que en dormir sólo se emplea; sólo ella es lisonjera y en un todo a medida de mi idea la vida es sueño, bien lo he conocido

1. talegas: «Cantidad de 1.000 pesos duros en plata» (DRAE). 
pues dejé lo soñado por dormido.

Sueña el triste que llora

sin hallar a su pena algún consuelo,

pero el que duerme ignora

el talento doblar que le dio el cielo,

en durmiendo con tema [repetida],

que cuento que el sueño es como la vida.

\section{Jornada tercera}

DON JosÉ PÉREZ

Si la verdad he de hablar, es cuento esto de vivir.

Si todo ha de ser argüir y nada se ha de soñar, no me quiero fatigar en llegar a discurrir si un efecto producir pueden dos causas totales, cuando conclusiones tales de nada me han de [servir]. Es el sueño un proteo ${ }^{2}$, que con modo tan vario vestir sabe cuanto excede al deseo y en la imaginación tan sólo cabe; el fingir emperadores hace reyes y a su arbitrio deroga y da las leyes. ¿Con qué habrá impedimento para que fingir pueda acá en mi idea?

No obstante, ¿qué argumento supe poner jamás en la tierra, que aunque en el sueño me mantuve mudo, ninguno como yo ser sabio pudo?

EL POETA

Así hablaban en la escena estos actores dormidos, queriendo con los ronquidos hacer un papel que sueña; de su discurso era ajena la más ligera cuestión. No los oí proposición ni acorde ni disparada ${ }^{3}$; si eran las premisas nada, dormir fue la conclusión.

Cayó el telón, cubriose el teatro y desde luego se me figuró una máscara o mojiganga que componían don José Antonio Rodríguez, don José Manuel

2. proteo: «Hombre que cambia frecuentemente de opiniones y afectos» (DRAE).

3. disparada: Participio de pasado de disparar («Metafóricamente vale decir o hacer cosas fuera de propósito y razón. Puede ser síncopa de disparatar», Aut.). 
Mauriño, don José María Bocarando y don Atanasio Aedo. Traían su danza que formaban don Lorenzo Pérez, don Francisco Mendivil, don Miguel Arenal, don José Manuel Villarelo y don José María Aguilar, y al compás de un órgano y un violín que tocaban don Martín Mauleon y don Mariano Gallegos. Unos daban pasos concertados y otros estaban concertados en no dar paso.

Venía don José Antonio Rodríguez a caballo en la misma [figura] que pinta el famoso Miguel de Cervantes al ingenioso [hidalgo] don Quijote de la Mancha, bien que el mismo Rodríguez aunque no tenía lo ingenioso de este héroe, tenía lo Quijote. Como digo, pues, en mi sueño traía su lanza y escudo, con la celada cubierto el rostro y la cabalgadura, cuyos lomos oprimía tan flaca, que más de cuatro zopilotes ${ }^{4}$ la miraban con ojos tiernos, creyendo que a cada paso caería muerta, pues tan al vivo representaba un esqueleto. Don José Manuel Mauriño montaba un jumento que me figuró al rucio de Sancho Panza imitando en todo a este leal escudero, pues aun la máscara con que cubría la cara era muy semejante a la que se nos pinta en la historia, y aunque no es tonto en las producciones geniales que tiene, puede apostarlas al mismo Sancho Panza. En una ocasión se le propuso este enigma para que lo desatara:

\footnotetext{
¿Quién es el león coronado, vario el color del vestido, que en el seno de su madre se comió a su padre vivo?
}

Inmediatamente respondió Mauriño: «El ratón» y, apurándole para que aplicase a este animal lo que se expresa en el enigma, dijo: «Yo no me calentaré la cabeza en andar combinando propiedades. Lo cierto es que en eso de comer a su padre vivo, el ratón es capaz de comer a su padre, a su madre y a toda su generación, pues no he conocido semejante heliogábalo» ${ }^{5}$. En otra ocasión se trataba de que desatase el siguiente:

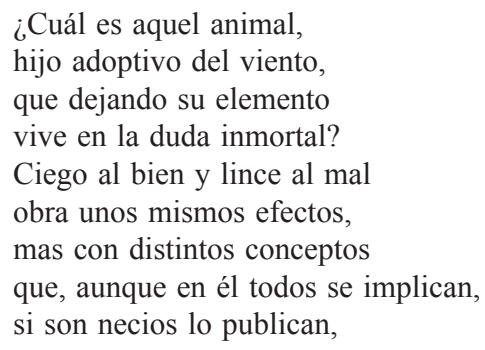

4. zopilote: «Ave rapaz diurna que se alimenta de carroña, de $60 \mathrm{~cm}$ de longitud y $145 \mathrm{~cm}$ de envergadura, de plumaje negro irisado, cabeza y cuello desprovistos de plumas, de color gris pizarra, cola corta y redondeada y patas grises. Vive desde el este y sur de los Estados Unidos hasta el centro de Chile y la Argentina» (DRAE).

5. heliogábalo: «Persona dominada por la gula» (DRAE). 
Propuesto que fue el enigma, respondió Mauriño sin detenerse: «[Eh], ya sé lo qué es: el mayate ${ }^{6}$, porque andando este animal tropezando con las paredes, puede decirse que es ciego, al bien [por]que no ve por donde anda y lince al mal porque sólo advierte en andar dando calabazadas».

Este caballero, pues, hacía a Sancho Panza, pero para que no faltase la gran Dulcinea del Toboso, don Atanasio Aedo hacía este papel vestido del mismo traje que traía aquella labradora, en quien transformaron los encantadores la bella dama de don Quijote, según lo persuadió al amo el bellaco del escudero. En la una mano traía un pendón con los versos que a su tiempo se dirán. Sentado pues a la mujeriega en una haca ${ }^{7}$ o bestia de albarda ${ }^{8}$, acompañaba a don José María Bocarando, que venía al pie del caballo de don Rodríguez imitando a la dueña Dolorida, con sus tocas muy reverendas y con los ojos llorosos, a guisa de suplicante, para que se le desficiera el entuerto que le traía de tan mal talante, a cuya demanda con el rostro mesurado, contestaba asimismo don Rodríguez:

- La tengo dicho a Vuestra Merced que el cielo me echó a luz para socorro de los menesterosos, y con ayuda de Dios y de aquella dulce enemiga mía - decía esto volviendo el rostro a don Atanasio Aedo-, que aunque los encantadores y malandrines que me persiguen hayan trocado su color volviéndolo moreno y disfrazado su hermosura bajo el tosco velo de una soez aldeana, jamás podrán contrastar el valor de este esforzado brazo, que ha de ser todo el remedio de su cuita, dando felice cima a ese desafuero y desaguisado que la aflige.

Y más cuando la señora doña Dolorida, o como se llamase - [añadió] Mauriño-, es merecedora por su buen término de que mi [señor] don Quijote o don Rodríguez, que todo es uno, eche el [resto] a su inacabable valentía en su defensa, porque he oído [decir] que donde las dan las toman, y que no hace la zorra [en] un año, cuanto paga en una hora; pero a mí tanto se [me] da de lo que va como de lo que viene, y eso de pagar los azotes al verdugo, no me acomoda, pues ojos que no ven corazón que no siente.

- Calla — le dijo enfadado don Rodríguez-, que ignoro a qué vienen tantos refranes como has ensartado en un momento, más a propósito eres para una nochebuena que para escudero de un caballero andante.

—Entiendo bien la sátira ${ }^{9}$ — replicó Mauriño_, y conozco que me ha dicho Vuesa Merced, en términos disfrazados, que para hacer el papel de

6. mayate: «Escarabajo de distintos colores y de vuelo regular. Hombre homosexual» (DRAE).

7. haca: Ya en desuso, es lo mismo que jaca.

8. bestia de albarda: es un asno y «era usado como fórmula en las sentencias de causas criminales cuando se condenaba al reo a un castigo afrentoso» (DRAE).

9. La referencia parece aludir a las representaciones de coloquios navideños, como luego confirmará la réplica de Rodríguez. Parece que la «sátira en términos disfrazados» consiste en llamarle rústico al recriminarle de ser sólo capaz sólo de representar papeles de pastores en pastorelas navideñas, y tener poca fluidez verbal, al llamarle Bato. El reproche se retoma en las siguientes quintillas que le dedicará el autor como colofón. 
Bato $^{10}$ en algún coloquio por tiempo de navidad tengo bastante suficiencia. Es cierto que soy sencillo por naturaleza, pero con algunos ribetes de malicioso. Pero ojo al tres, que si yo soy a propósito para pastor, otros son para nada.

Las siguientes boleras ${ }^{11}$ que cantará la música, explicarán lo que dije al mal andante caballero:

Otro papel no he hallado

que le acomode,

mi señor don Rodríguez,

que el de Quijote;

de mal talante

parece que le he visto,

pero adelante.

Es su rocín muy flaco ${ }^{12}$,

largo de cuerpo,

amarillo su rostro,

muy quijotesco.

$\mathrm{Y}$ aunque es muy cierto

que esto pasa por dicho,

es dicho de hecho.

Luego que te vi, dije,

del caballero

de la triste figura

eres remedos,

y es caso llano

que desfacer entuertos

es de tu cargo.

Las aventuras quiere

el que las busca,

pero salir bien de ellas

es por ventura.

Tendrás presente

cuanto muelen los palos

de los yangüeses ${ }^{13}$.

Después de una contienda,

ya te lo aviso,

saldrás escarmentado

y asaz ferido,

pero no te hace

si eres la flor y espuma

de los andantes.

10. Bato: personaje de la mitología griega asociado a la tartamudez.

11. boleras: "Aire musical popular español, cantable y bailable en compás ternario y de movimiento majestuoso» (DRAE).

12. Parecería que todos los apelativos que se dirigen a Rocinante podrían aplicarse también al propio Rodríguez.

13. yangüeses: gentilicio de Yanguas. Alude al Quijote (I, 15). 
Encontrarás castillos, y no lo dudes en que te burlen tanto como el vil duque;

Altisidora,

la Trifaldi y la Dueña

te han de hacer mofa ${ }^{14}$

Tengo presente que después dije a don José Manuel Mauriño:

Tienes mucha semejanza, no sólo en las producciones, sino aun en muchas acciones con el grande Sancho Panza.

Esto sólo es una chanza, pero diré, desde luego, que pues no bastó mi ruego y que estudiar no quisiste, si con los bobos dormiste, entre bobos anda el juego ${ }^{15}$. Que se agua a tu parecer el vejamen no lo digas, porque sin tu ajo las migas muy bien se sabrán hacer. Contribuir no es menester ni que asistas se requiere $\mathrm{y}$, si alguno presumiere que no sé hablar cara a cara, como si aquí te mirara, he de hablar de donde diere.

Continuamente mostrabas lo sencillo en discurrir; por Bato habías de salir con la batea de las babas. Siempre de Belén tratabas y no te sonaba mal del Dios nacido el portal, que teniendo oficio en él te llevaba a hacer papel la inclinación natural.

Cuando así adivinar quieres de Bato te calificas, pues que nunca especificas tus cándidos pareceres; dispara como quisieres

14. Además del duque, los otros dos personajes que se aluden de la novela (Altisadora y la condesa Trifaldi), intervienen en los capítulos de la estancia de don Quijote y Sancho en el castillo del noble aragonés.

15. Referencia a la comedia de Rojas Zorrilla. 
y porfía sin fundamento, que yo decir sólo intento que a muchos inficionaste y lo bobo les pegaste, que un bobo sólo hace ciento $^{16}$. $\quad 40$

Así hablaba a este caballero, cuando reflexionando en la figura rara de don Atanasio Aedo del Toboso, digo de doña Dulcinea del Toboso, no pude contener mi musa, que desde luego se desató en los versos siguientes ${ }^{17}$ :

Eres la gran Dulcinéquerida del gran Quijo-, por quien los encantadodisfrazaron tu belle-.

Esto es lo que trae inquiede tu dueño don Rodri-. ¡Oh Quijote, que es todo u-, pues de tu ausencia la pulo tiene asaz mal feri-!

Y pues es tiempo que se sepa el contenido de aquellos versos que venían escritos en el pendón, silencio y al caso:

1

En este traje mudada, que es muy proprio de la aldea, se queja desfigurada y en labradora trocada, la agraciada Dulcinea del Toboso.

2

Es la envidia maliciosa

la que la ha puesto tan fea $\mathrm{y}$, aunque era princesa hermosa, es la suerte lastimosa de la sin par Dulcinea del Toboso

\section{3}

Es muy rara su mudanza por que su caída se vea; y el bellaco Sancho Panza

16. Referencia a la comedia de Antonio de Solís.

17. Las siguientes quintillas de cabo roto recuerdan, por el recurso jocoso de los versoso truncados a partir de la última sílaba acentuada, a las décimas de Urganda al frente del Quijote. 
dice que no es semejanza

de la que era Dulcinea

del Toboso.

4

La que excedía en hermosura

a la bella Casildea,

ahora no es ni su figura.

Tanta así es la desventura

de la sin par Dulcinea

del Toboso.

5

A Sancho le ha de costar, que es de muy baja ralea, de azotes más de un millar el poder desencantar a la hermosa Dulcinea del Toboso.

Oídos, que tales orejas respondió Mauriño:

-Que no me daré yo un azote, aunque se quedasen encantadas todas las dulcineas del mundo. ¿Qué tienen que ver mis carnes con su encantamento? Y más cuando yo no he parido a esa señora imaginaria del Toboso que se le ha venido a las mientes a mi señor don Rodríguez, que tal sea mi salud; como yo creo que es una locura antojadiza, pero suponiendo que yo no me he de dar ni un azote ni medio, porque esto es pedir peras al olmo, sería bueno que a esta doña Dolorida...

—Dueña, querrás decir, que no doña, Sancho - le interrumpió don Rodríguez-.

—Doña o dueña — replicó Mauriño- Todo sale allá, decía, pues, que sería muy razonable dar a esta señora que viene aquí no más girimiqueando ${ }^{18}$ un pasalomo ${ }^{19}$ para que enjugase sus lágrimas, que cierto que tengo el corazón muy doloroso de verla tan plaguienta.

—Eso haré de buena gana — le respondí—, aunque digan que...

Musica in luctu, intempestiva narrati.

\author{
1 \\ La dueña Dolorida \\ que representas \\ es para con tu llanto \\ niña de teta. \\ Tan llorona eres,
}

18. girimiquear: Lo mismo que gimotear (Santamaría, 1983, p. 558).

19. pasalomo: Por el contexto se entiende que se trata de algún tipo de paño. 
que una vieja a tu lado

moza parece.

2

Si de todo te apuras

y compadeces,

padeces tantos males

cuantos adviertes.

No son bastantes

a dar [agua] a tus ojos

todos [los] mares.

3

Ese desaguisado

que te atormenta, tormenta ha levantado de muchas penas.

No poca parte

le cabe a don Rodríguez

de tus pesares.

4

Si [lloras] de tu cuita [en el] empeño,

empeño es y no hay duda, pero muy tierno.

Ten por sabido

que el sueño a aquél que llora siempre se le ha ido.

5

Menos que tú por su asno

Sancho suspira,

pira es de compasión

la Dolorida,

y no de fuego,

que tanta agua apagara

cualquiera incendio.

6

Déjate pues de ruegos, no estés hablando.

Blando es, y mucho, el pecho

de nuestro hidalgo.

$\mathrm{Y}$ en el consuelo

que inauditas fazañas

hará su esfuerzo. 